An Experimental Examination of the Simultaneous Determination of Input Prices and Output Prices

Author(s): Jessica Goodfellow and Charles R. Plott

Source: Southern Economic Journal, Vol. 56, No. 4 (Apr., 1990), pp. 969-983

Published by: Southern Economic Association

Stable URL: http://www.jstor.org/stable/1059885

Accessed: 03/03/2014 17:47

Your use of the JSTOR archive indicates your acceptance of the Terms \& Conditions of Use, available at http://www.jstor.org/page/info/about/policies/terms.jsp

JSTOR is a not-for-profit service that helps scholars, researchers, and students discover, use, and build upon a wide range of content in a trusted digital archive. We use information technology and tools to increase productivity and facilitate new forms of scholarship. For more information about JSTOR, please contact support@jstor.org. 


\title{
An Experimental Examination of the Simultaneous Determination of Input Prices and Output Prices*
}

\author{
JESSICA GOODFELLOW \\ CHARLES R. PLOTT \\ California Institute of Technology \\ Pasadena, California
}

\section{Introduction}

This paper involves a test of the competitive equilibrium as a model of the interdependence that exists between input and output markets. The test was motivated by the questions of skeptical students who were just learning the details of the competitive model. It was also motivated as a natural extension of existing results. In essence, the interdependence between input and output markets has been observed in several laboratory studies in which arbitrage could occur in markets separated by space or by time $[6,599-624 ; 5 ; 8,1063-1071 ; 3,223-241 ; 1,537-567 ; 2,955-$ $981 ; 7,106-127 ; 9,1-33]$. Goods acquired by an arbitrager or by a speculator can be viewed as inputs taken from one market and then when sold by the same agent in a spatially separated or a temporarily separated market, they can be viewed as outputs resulting from a simple production process. Thus, all experiments in which such market activity exists can be viewed as having involved production. However, in all cases studied to date the market interdependence was rather transparent and the production technology was linear. In this study, the problem posed for the multiple markets is not transparent and the technology is nonlinear.

The exposition is developed so that the complexity of the model and the situation can be appreciated by readers who have not attempted to work through the details of the competitive model. The competitive model involves an extraordinary number of definitions and behavioral hypotheses, any of which might be unrealistic. All of them are part of the resulting model and predictions but they are frequently buried in axioms and exist implicitly in notation and definitions. The strategy of this paper is to solve the model showing at each step the definition or behavioral hypothesis that is applied so that all of the theoretical machinery is covered. The purpose is to provide data that show that interdependent markets can grapple with a complex problem essentially in the way that the theory suggests. The paper provides no substantial conclusions about the fine aspects of theory. Whether or not markets can always do it or how markets do it is not addressed. Section I describes the experimental setting. Section II develops the model and section III contains the data.

*The financial support of The National Science Foundation is gratefully acknowledged. 
Table I. Marginal Redemption Value Table for Each of Six Buyers of $x$

\begin{tabular}{cc}
\hline Unit & $\begin{array}{c}\text { Redemption Value } \\
\text { (in cents) }\end{array}$ \\
\hline 1 & 98 \\
2 & 88 \\
3 & 78 \\
4 & 70 \\
5 & 60 \\
6 & 50 \\
7 & 43 \\
8 & 33 \\
9 & 25 \\
10 & 15 \\
11 & 10 \\
12 (and more) & 0 \\
\hline
\end{tabular}

Table II. Marginal Cost Schedule for Six Sellers of $y$ (in Cents)

\begin{tabular}{lrrrrrr}
\hline & \multicolumn{7}{c}{ Seller Number } \\
\cline { 2 - 7 } Unit & \multicolumn{1}{c}{1} & \multicolumn{1}{c}{3} & \multicolumn{1}{c}{4} & \multicolumn{1}{c}{5} & 6 \\
\hline 1 & 10 & 35 & 50 & 65 & 80 & 100 \\
2 & 150 & 165 & 180 & 205 & 130 & 115 \\
3 & 275 & 310 & 255 & 295 & 235 & 220 \\
4 & 400 & 400 & 400 & 400 & 400 & 400 \\
5 & 1,000 & 1,000 & 1,000 & 1,000 & 1,000 & 1,000 \\
\hline
\end{tabular}

\section{The Experimental Setting}

The experimental setting involved two markets. One market is for output, called $x$, and the other market is for input, called $y$. The output market consisted of six buyers. Each buyer had the same induced value function shown on Table $I$. The input market contained six sellers with the induced cost function in Table II. In addition, there were four producers each of which had the production technology for producing $x$ that is contained in Table III. The parameters in the tables are in terms of dollars. Subjects were presented the redemption values and costs in terms of an artificial medium called francs. All trading took place in francs which could be converted to dollars at rates of 1 cent, 3 cents, and 4 cents per franc for buyers, sellers, and producers, respectively.

A total of four experiments were conducted. Subjects were students of a principles of economics class at the California Institute of Technology. Many of these subjects had participated in computerized multiple double-auction markets prior to these experiments. Experiment 4 involved mostly subjects with no prior experience at all. Instructions were read and a practice period was used to familiarize subjects with the trading technology.

Two markets were open simultaneously for a period of 10 minutes for the first few periods and then the time was reduced to 6 minutes. Producers were able to purchase $y$ and add it to their $y$ inventories. Once in inventory, $y$ could be transformed into $x$, according to Table III, by 
Table III. The Production Function $x_{i}=7 y_{i}-\left(y_{i}^{2} / 2\right)$

\begin{tabular}{lc}
\hline Input & Marginal Output \\
\hline 0 & 0 \\
1 & 7 \\
2 & 5 \\
3 & 5 \\
4 & 3 \\
5 & 3 \\
6 & 1 \\
7 & 1 \\
8 (and above) & 0 \\
\hline
\end{tabular}

hitting a function key. The "produced" $x$ appeared in the $x$-market inventory from which it could be sold.

The computerized multiple unit double-auction program [4] permits bids and asks for multiple units in both the $x$ and $y$ markets. Trades occur in real time. Production necessarily occurred in advance of sales and inventories could not be carried forward to the next period. Once produced, $x$ was perishable.

\section{The Model}

The model is a straightforward application of modern theory. The market demand for the output $x$ is computed. Market supply of $x$ is computed as a function of the price of the input $y$. This calculation involves a definition of a cost function, application of the profit maximization hypothesis and application of the definition of market supply as a sum of individual supplies. An application of the law of supply and demand allows the price of $x$ to be calculated as a function of the price of $y$. Derived demand theory yields the individual demands for $y$. Application of the definition of market demand and market supply allows these functions to be calculated as a sum of individual functions. The law of supply and demand can then be used to calculate the price of $y$ and the price of $y$ can be used to calculate all other magnitudes. In the analysis below each step in the application of the theory will be made explicit.

The first problem is to define a market demand function. The competitive model requires that only one price exists in a market. For the output market $x$, this price is denoted as $P$ and for the input market $y$ it is denoted as the lower case $p$. The competitive model requires that buyers and sellers are price takers and utility maximizers. From these definitions and maintained hypotheses the values in Table I can be used to create individual demand functions. The definition of market demand as a sum can be used to get the market demand function shown in Figure 1. A continuous approximation of the market demand is drawn as a dotted line. The equation for this approximation is:

$$
x_{d}=68(1-.01 P)
$$

when $P=$ the price of $x$.

By application of a similar set of postulates, the values in Table II can be used to get indi- 

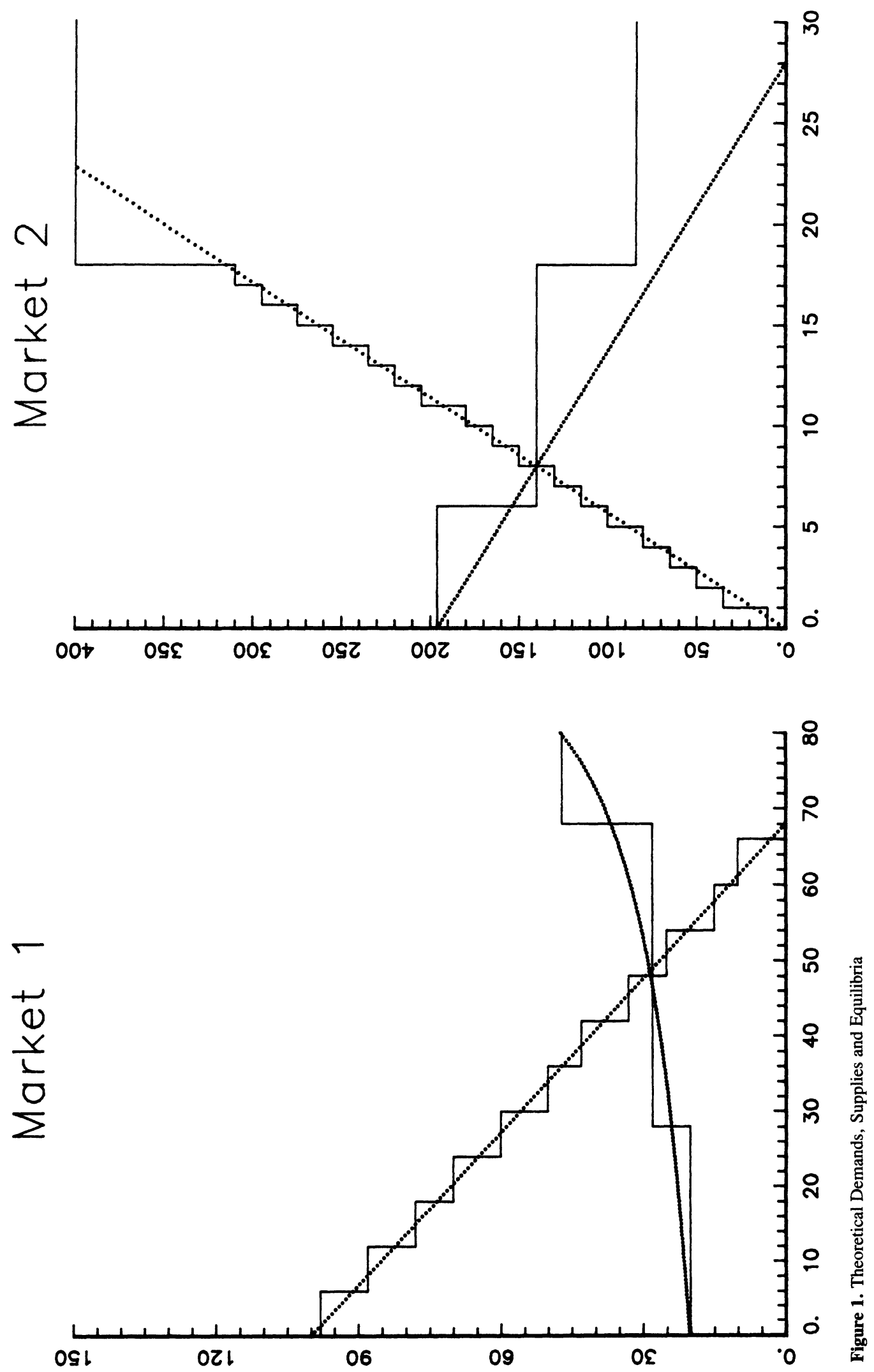
vidual supply functions for $y$. When these are aggregated, a market supply is obtained. The actual supply function is shown in Figure 1. A continuous approximation of market supply is given by the function

$$
y_{s}=(8 / 140) p
$$

where $p$ is the price of $y$.

This approximation is shown as a dotted line in the figure.

There are four agents with the ability to produce $x$ from inputs of $y$. Each has a production function

$$
x_{i}=7 y_{i}-\left(y_{i}^{2} / 2\right)
$$

where $\left(x_{i}, y_{i}\right)$ is the output and input level of agent $i$.

To find the equilibrium price of $x$ at any given price of $y$, as expressed in (14) below, requires that one obtain the individual supply functions from the four producers given by (10) below, sum them to get market supply given by (11), and then use the law of supply and demand at (12). The theory and derivations are as follows.

From the profit maximization hypothesis and the law of one price in a competitive market the producers' decisions become:

$$
\max _{x_{i}} P x_{i}-C\left(x_{i}\right)
$$

From (4) we get the behavioral equation (first order conditions)

$$
P-C^{\prime}\left(x_{i}\right)=0 .
$$

The definition of $C\left(x_{i}\right)$ is

$$
C\left(x_{i}\right)=p y_{i}
$$

so using the competitive hypothesis that price is a constant one gets

$$
C^{\prime}\left(x_{i}\right)=p\left(d y_{i} / d x_{i}\right)
$$

Since there is only one input, the binomial formula can be applied to (3) to get $y_{i}=$ $7-\left(7^{2}-2 x_{i}\right)^{1 / 2}$. So we have

$$
\left(d y_{i} / d x_{i}\right)=\left(7^{2}-2 x_{i}\right)^{-1 / 2}
$$

Substituting (8) into (7) and the results into (5) we obtain for each $i$

$$
P=p\left(49-2 x_{i}\right)^{1 / 2}
$$

Solve for $x_{i}$ to get the individual firm supply function for $x$

$$
x_{i}=\left[49-(p / P)^{2}\right] / 2 .
$$


Use (10) and the definition of market supply as the sum of individual supply functions to get

$$
x_{s}=4 x_{i}=4\left\{\left[49-(p / P)^{2}\right] / 2\right\}=98-2(p / P)^{2} .
$$

In order to find the equilibrium $P$ apply the law of supply and demand to the $x$ market

$$
x_{d}=x_{s}
$$

Substitute from (1) and (11) and the law becomes

$$
68(1-.01 P)=98-2(p / P)^{2}
$$

Simplify to

$$
\left(p^{2} / P^{2}\right)-.34 P=15
$$

The solution to this yields the equilibrium $P$ expressed as a function of $p$.

To find the equilibrium price of $y$, i.e., $p$, one must find the demand for $y$ and then apply the law of supply and demand to find the equilibrium price.

To find market demand for $y$, the individual demand functions must be derived. From the profit maximization hypothesis one has

$$
\max _{y_{i}} P x_{i}-p y_{i}
$$

Substitution from (3) yields

$$
\max _{y_{i}} P\left[7 y_{i}-\left(y_{i}^{2} / 2\right]-p y_{i} .\right.
$$

From the first order conditions and competitive market assumptions (prices are constants), we get

$$
P\left(\partial x_{i} / \partial y_{i}\right)-p=0 \text {. }
$$

From differentiation of (3) we get

$$
P\left(7-y_{i}\right)=p
$$

Solve for $y_{i}$ to get individual demand function for $y$

$$
y_{i}=7-(p / P) .
$$

The market demand function is the sum of individual demands from the 4 demanders under competition

$$
y_{d}=4[7-(p / P)]
$$

In order to find the equilibrium price of $y$ as given in (23) below, apply the law of supply and demand 


$$
y_{d}=y_{s}
$$

Substitute from (20) and (2) to get

$$
4[7-(p / P)]=(8 / 140) p .
$$

Solve to get the equilibrium price of $y$

$$
p=490 P / P+70
$$

In order for both markets to be in equilibrium, the equilibrium prices $P$ and $p$ must satisfy both equilibrium equations (14) and (23) simultaneously. Substitute (23) into (14) to obtain

$$
\left(1 / P^{2}\right)[(490 P) /(P+70)]^{2}-.34 P=15
$$

which simplifies a little to

$$
490^{2} /(P+70)^{2}-.34 P=15
$$

The equation is a third degree polynomial of which one root is the equilibrium price. Solving and then solving for quantities from (1) and (2) the equilibrium prices and quantities are

$$
\begin{array}{ll}
P=28.57 & x=48 \\
p=142.02 & y=8.12 .
\end{array}
$$

These magnitudes are predicted as the general equilibrium by the competitive model.

The above model is continuous. The discrete values it approximates are in Figure 1. As can be seen, the equilibrium prices are 28 in the $x$ market and 140 in the $y$ market. Ordinarily a trading commission of a few cents is necessary to facilitate trades so it would not be unreasonable to expect the $y$ market prices to be below these predicted prices by 5 cents ( 2 francs) or so and the $x$ market to be above these prices by a similar magnitude.

\section{Results}

Four experiments were conducted. The time series of prices and contracts are in Figures 2-5. For example, in Experiment 1 and period 1 of the $x$ market shown in Figure 2, the first unit sold at a price of approximately 97 francs and the second unit sold for about 95 francs. The thirtythree dots on the graph represent thirty-three units traded that period. As can be seen, prices fall throughout the period with the last trade at about 50. The data are imposed over the dotted lines which are the competitive prices predicted by the competitive model.

The average prices, volumes and efficiencies are in Table IV. For the last period average prices $(P, p)$ are $(27.7,129),(23.4,135.2),(35.1,144),(33.1,155.7)$ for experiments $1,2,3$, and 4 , respectively. These compare favorably to the equilibrium values $(28,142)$. The volumes $(x, y)$ are $(43,7),(54,9),(56,9)$, and $(43,7)$ in the three experiments and these compare favorably to the equilibrium values of $(48,8)$. As can be seen, the data are close to the model in the 

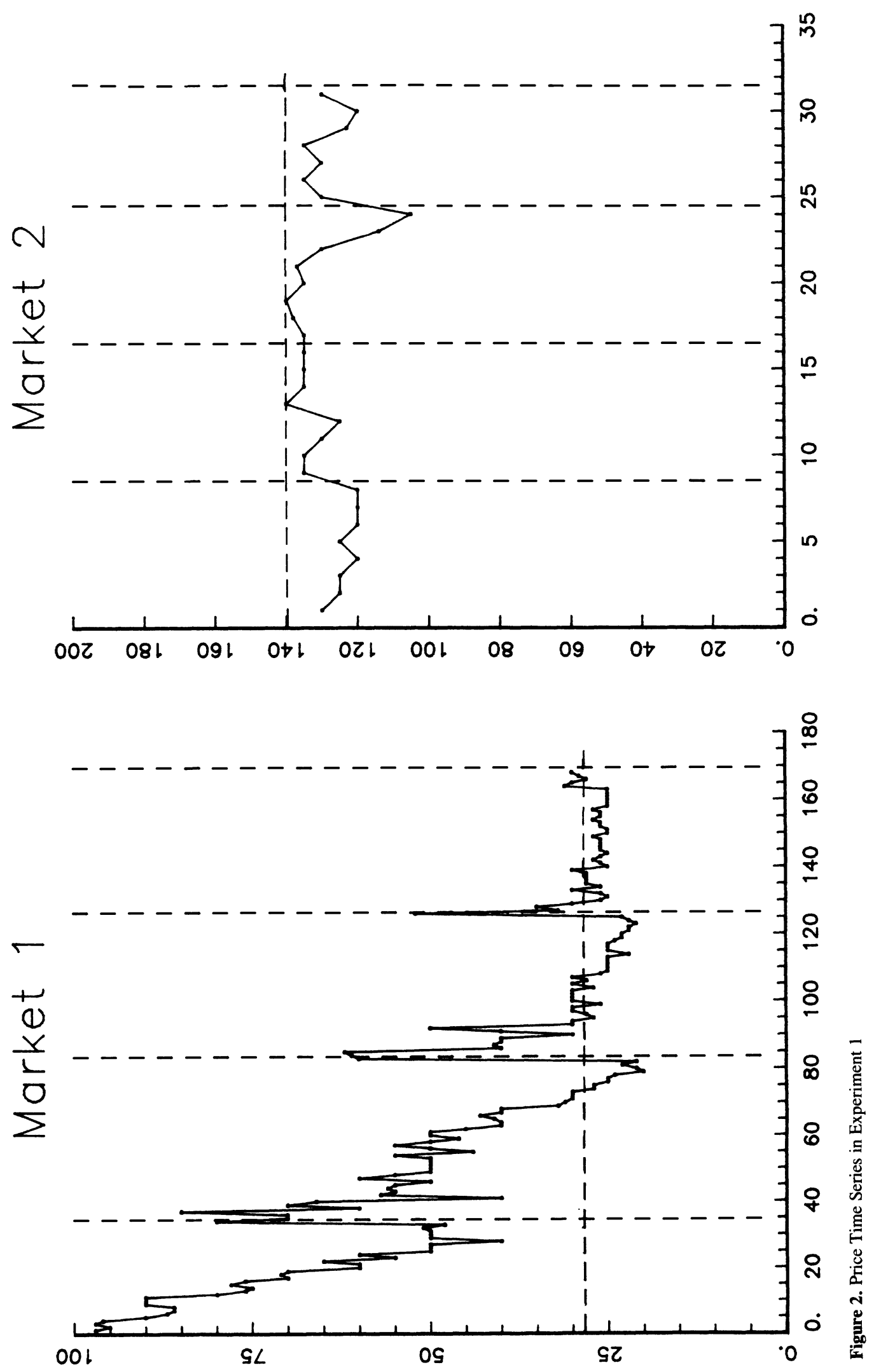

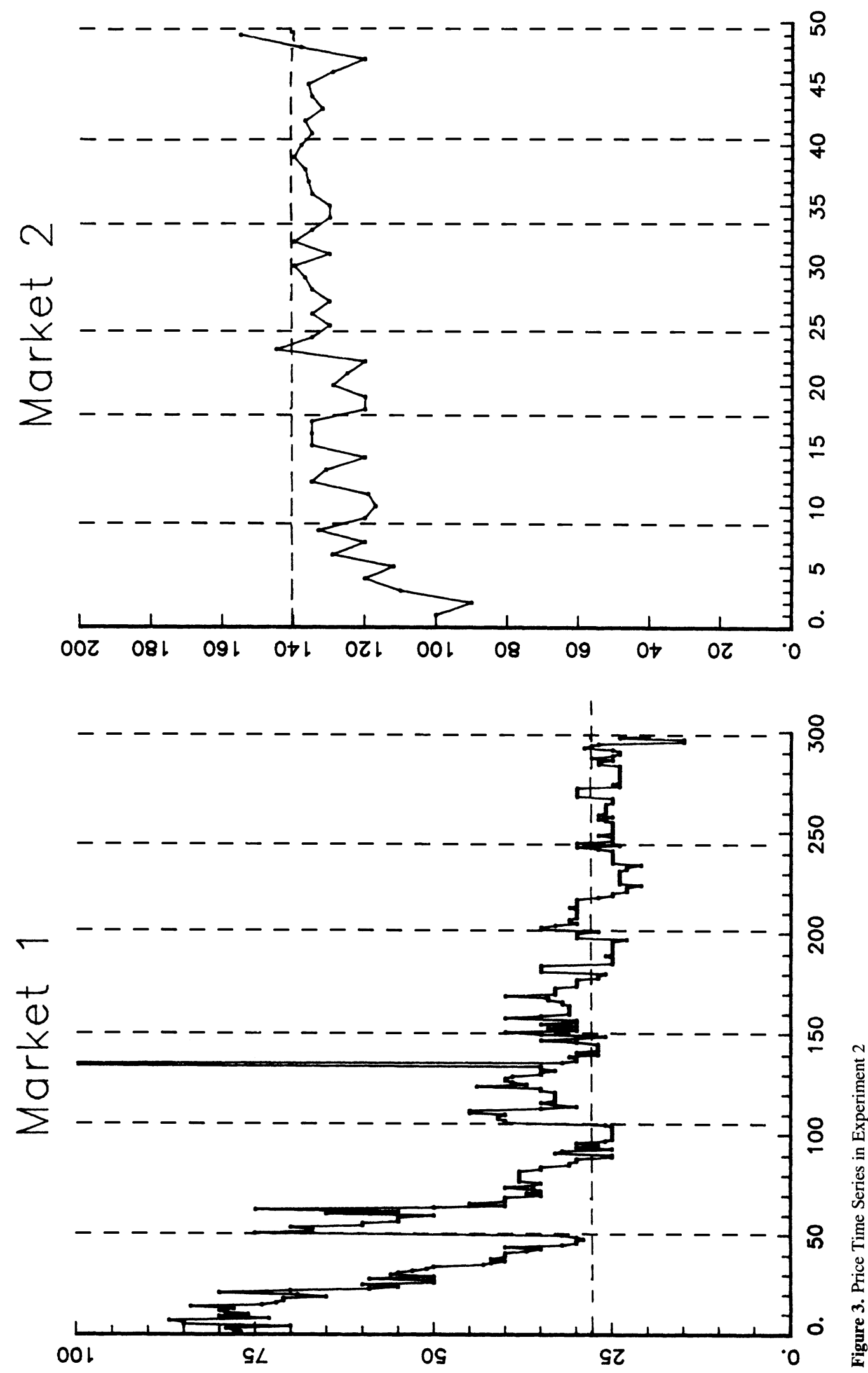

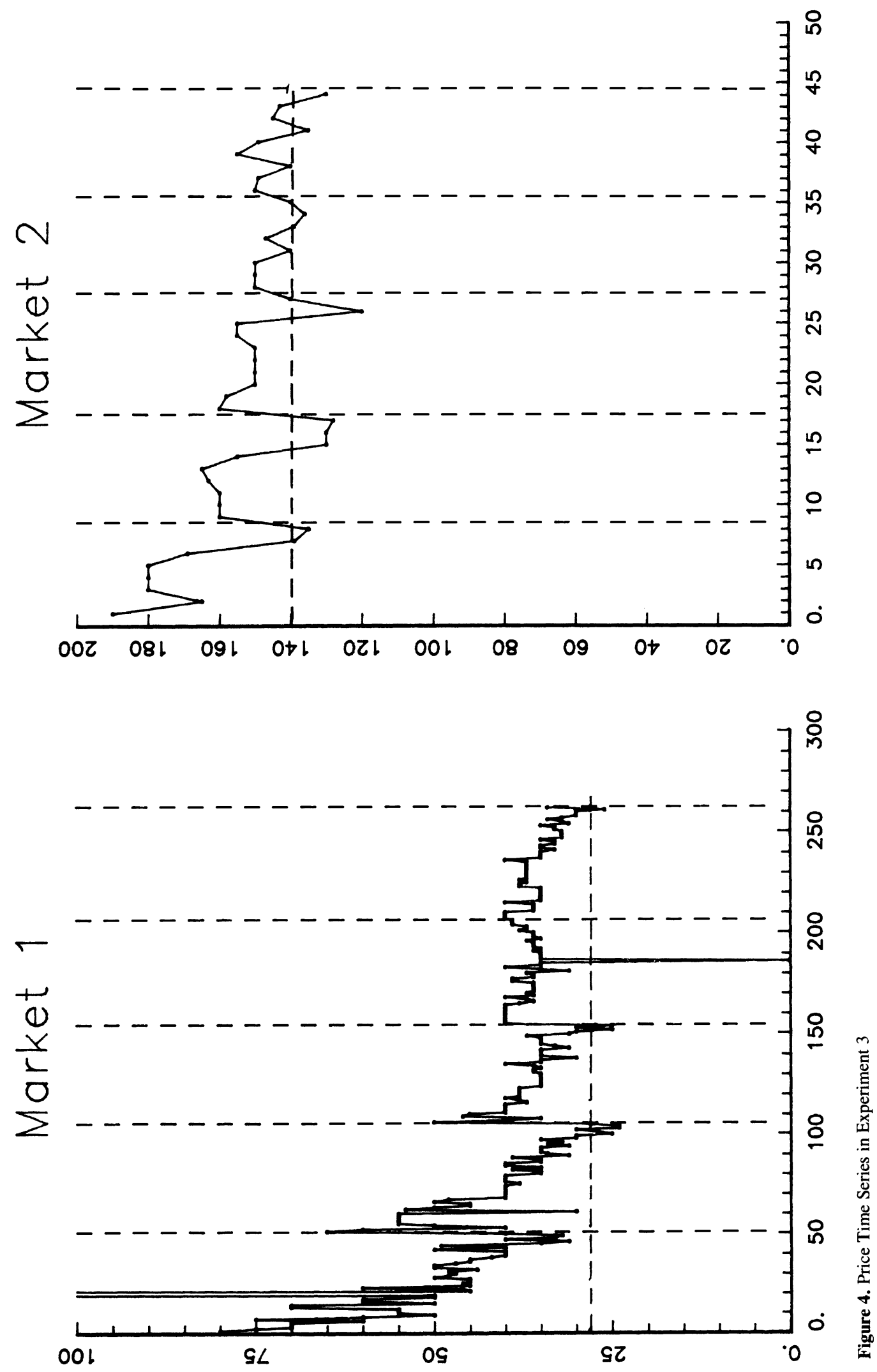

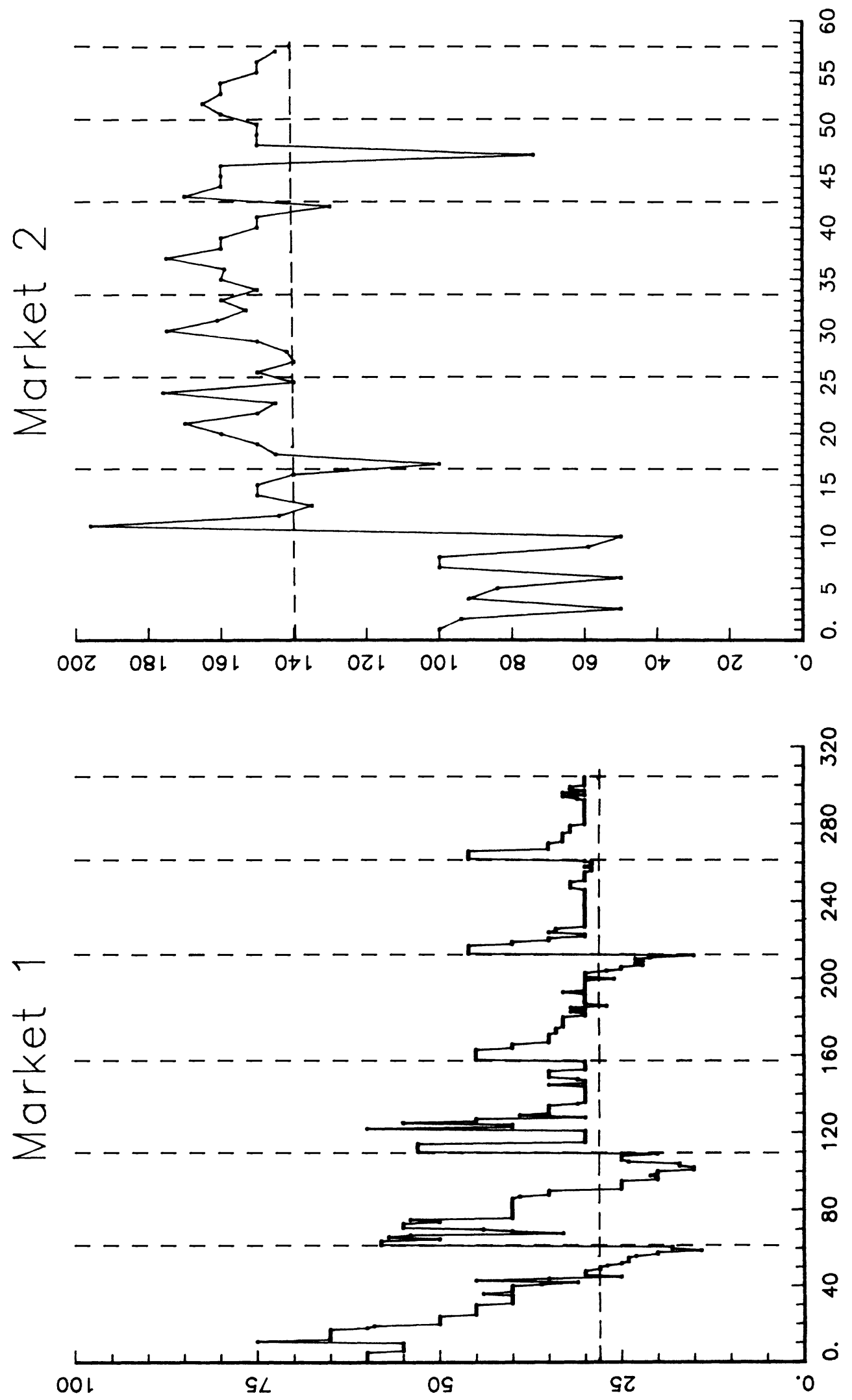
Table IV. Average Prices, Volume and Efficiency

\begin{tabular}{|c|c|c|c|c|c|c|}
\hline \multirow[b]{2}{*}{ Experiment } & \multirow[b]{2}{*}{ Period } & \multicolumn{2}{|c|}{$x$ Market } & \multicolumn{2}{|c|}{$y$ Market } & \multirow[b]{2}{*}{ System Efficiency } \\
\hline & & Average Price & $\begin{array}{c}\text { Production } \\
\text { Volume* }\end{array}$ & Average Price & $\begin{array}{c}\text { Production } \\
\text { Volume* }\end{array}$ & \\
\hline \multirow[t]{4}{*}{1} & 1 & 70.9 & 30 & 123.1 & 6 & .77 \\
\hline & 2 & 45.6 & 48 & 133.8 & 8 & .96 \\
\hline & 3 & 30.9 & 43 & 129.3 & 8 & .91 \\
\hline & 4 & 27.7 & 43 & 129.0 & 7 & .98 \\
\hline \multirow[t]{6}{*}{2} & 1 & 58.3 & 48 & 114.2 & 8 & .96 \\
\hline & 2 & 40.0 & 47 & 127.4 & 8 & .99 \\
\hline & 3 & 34.6 & 41 & 127.7 & 7 & .93 \\
\hline & 4 & 30.3 & 48 & 134.7 & 8 & 1.00 \\
\hline & 5 & 26.8 & 43 & 135.1 & 7 & .83 \\
\hline & 6 & 23.4 & 53 & 135.2 & 9 & .97 \\
\hline \multirow[t]{5}{*}{3} & 1 & 50.1 & 44 & 167.3 & 8 & .91 \\
\hline & 2 & 40.1 & 49 & 150.1 & 9 & .88 \\
\hline & 3 & 36.1 & 47 & 148.8 & 8 & .97 \\
\hline & 4 & 37.2 & 48 & 144.0 & 8 & .98 \\
\hline & 5 & 35.1 & 49 & 144.0 & 9 & .95 \\
\hline \multirow[t]{6}{*}{4} & 1 & 44.7 & 56 & 102.9 & 15 & .09 \\
\hline & 2 & 35.5 & 48 & 148.4 & 9 & .89 \\
\hline & 3 & 35.9 & 48 & 153.8 & 8 & .98 \\
\hline & 4 & 32.0 & 53 & 154.9 & 9 & .93 \\
\hline & 5 & 32.6 & 48 & 159.3 & 8 & 1.00 \\
\hline & 6 & 33.1 & 43 & 155.7 & 7 & .98 \\
\hline \multicolumn{7}{|l|}{ Competitive } \\
\hline Equilibrium & & 28 & 48 & 142 & 8 & 100 \\
\hline
\end{tabular}

*Market volume can differ from these numbers because of trading between producers.

sense that one would expect a very different distribution from simply random behavior of prices and volume. Furthermore, if one accepts the double exponential model as a representation of the data, prices are converging to the equilibrium. ${ }^{1}$

1. We introduce the double exponential adjustment model as a tool to explore the visual impression that prices are converging to the competitive equilibrium. While the model is ad hoc in the sense that it has no theoretical justification, it is nevertheless a tool that permits us to make objective statements about the patterns in the data.

The model for any given market is

$$
\left|P_{t c}-P^{*}\right|=a e^{\beta t+\gamma c}
$$

where

$$
\begin{aligned}
t & =\text { period number } \\
c & =\text { contract (transaction) number in the period } \\
P^{*} & =\text { competitive equilibrium price. }
\end{aligned}
$$

To the extent that this model is a representation of the data, prices are converging to the competitive equilibrium between periods if $\beta<0$ and within periods if $\gamma<0$. The parameter $a$ measures the distance from equilibrium at the beginning of the experiment in francs. If $a=0$ then the markets opened at equilibrium and neither $\beta$ or $\gamma$ need be different from zero.

As shown in Table $\mathrm{V}$, the $\beta$ 's and $\gamma$ 's tend to be negative and significant. The exceptions are the coefficient for $c$ in market 2 of experiments 1 and 2 . In both of these markets $\gamma$ is positive. Notice, however, that in both of these markets 
Efficiency refers to the actual consumers' plus producers' surplus taken as a percentage of the maximum possible. Operationally, efficiency is the total of redemption values received by the final holders of $x$ minus the total of costs paid by the initial suppliers of $y$. The difference between the two totals is a measure of consumer plus producer surplus generated by the market. The efficiency measure is the difference between the totals taken as a percentage of the maximum possible difference. The maximum possible in attained efficiency is 100 percent (which is predicted by the competitive model).

The efficiency numbers in Table IV do not reveal the usual monotonic properties of market efficiency time series. Usually efficiency starts low and slowly climbs as experience leads to fewer wasted units and the competitive equilibrium is approached. By contrast, efficiency in three of the four markets starts high and stays high. These high figures tell us that the deviations from the competitive equilibrium do not involve large losses of gains from exchange. In evaluating the success of the markets in coordinating exchanges, it is important to realize that without production and trade the efficiency levels would be zero. These markets, starting from a floor of nothing, almost completely exhausted such gains from exchange that were possible.

\section{Concluding Remarks}

These data focus attention on interesting methodological problems that have surfaced in the profession from time to time regarding the best way to "test" models. Should a model be judged by the validity of its assumptions or simply the accuracy of its predictions? What degree of accuracy should be applied? Which predictions are to be tested? The data provide a good example of the use of the "as if" methodology and the nature of the controversy it can generate.

On one hand, a casual look at the data is sufficient to show that many of the assumptions of the competitive equilibrium model are false when the model is applied to these markets. In particular:

(a) The law of one price in a competitive market does not hold in these markets. Therefore the variables $P$ and $p$ in the competitive model are without unique operational definitions.

(b) Individuals do not take prices as constants. The variance in prices reflects attempts to force a "better deal by agents."

(c) People do not optimize. "Unused" inventories that appear from time to time reflect losses that could have been avoided by selling the units.

(d) The markets do not attain an immediate equilibrium if indeed they ever "equilibrate" in the sense of no changes.

(e) If $P$ and $p$ are measured as average prices, then the price predictions are wrong (by a few cents).

initial prices are near the equilibrium as measured by $a e^{\beta+\gamma}$ (9 francs and 15 francs, respectively) so no pronounced convergence process is detected in the intraperiod measures even though movement is noticeable in the interperiod measure.

While this model is useful as a measure of price movements a word of caution is necessary. The Durbin-Watson tests are included in the table as a warning that the model involves substantial autocorrelation. While AR1 corrections and weighted least squares (for heteroscedasticity) can be applied to get $t$-statistics down and $R^{2}$ up, such statistical massaging seems to simply mask a more fundamental problem of specification. 
Table V. Coefficients ( $t$-Statistics*), Number of Observations, $R^{2}$ and Durbin-Watson Test for the Model $\ln \left|P_{t c}-P_{e}\right|=\alpha+\beta t+\gamma c$

\begin{tabular}{lccccccc}
\hline Experiment\# & Market\# & $\alpha$ & $\beta$ & $\gamma$ & $n$ & $R^{2}$ & DW \\
\hline 1 & 1 & 5.244 & -.951 & -.036 & 167 & .723 & .537 \\
& & $(25.314)$ & $(-18.358)$ & $(-8.420)$ & & & \\
& 2 & 2.189 & -.111 & .104 & 31 & .150 & 1.079 \\
& & $(3.021)$ & $(-1.007)$ & $(1.902)$ & & & \\
& 1 & 3.648 & -.378 & -.208 & 276 & .494 & .478 \\
& & $(20.007)$ & $(-14.210)$ & $(-8.144)$ & & & \\
& 2 & 2.810 & -.180 & .048 & 48 & .184 & 1.193 \\
3 & & $(6.427)$ & $(-2.546)$ & $(2.380)$ & & & \\
& 1 & 3.588 & -.203 & -.029 & 245 & .548 & 1.214 \\
& & $(28.982)$ & $(-9.278)$ & $(-14.017)$ & & & \\
& 2 & 4.072 & -.398 & -.138 & 40 & .519 & 1.977 \\
4 & & $(9.829)$ & $(-5.344)$ & $(-3.135)$ & & & \\
& & 3.632 & -.389 & -.014 & 281 & .382 & .575 \\
& & $(17.273)$ & $(-12.901)$ & $(-3.750)$ & & & \\
& 2 & 3.934 & -.179 & -.119 & 54 & .160 & 1.319 \\
& & $(6.979)$ & $(2.217)$ & $(-2.868)$ & & & \\
\hline
\end{tabular}

*The $t$-statistic for $\alpha$ is for significant difference from 1 while the other two are for significant difference from 0 .

Thus, scholars who are uncomfortable with the application of a model to cases in which the assumptions are not true can find substantial reasons for not applying the competitive model. A methodology that requires a literal interpretation and application of theory would force one to conclude that the competitive model can be rejected as having incorporated incorrect assumptions and having made predictions that are false.

On the other hand, it is the case that aspects of the markets behave substantially "as if" the competitive assumptions were satisfied. A methodology that prevents an application of the model as a means of organizing the data would force one to ignore much of what the data can teach us about behavior. Application of the "as if" philosophy has benefits. Relative to the model, the following generalizations are consistent with observations.

(a) A convergence process is occurring in both markets. With stationary parameters the market system is converging in the direction of the competitive equilibrium.

(b) After a few periods the data are "close" to the competitive equilibrium in the sense that no other model (based on initial parameters) does better. ${ }^{2}$

(c) Even though the assumptions of the competitive model are false they appear to capture the essence of extremely complex phenomena. No other assumptions drawn from any other academic discipline have the dual claim of tractability and reasonable accuracy of a resulting model.

In spite of its mathematical complexity, the competitive model is very crude when placed in the context of these interactive markets and behaviors. Nevertheless, if the assumptions of the

2. The Cournot model when applied to the continuous approximation of the market parameters produces similar outcome predictions. 
model are applied with an "as if" interpretation, the resulting model is very powerful. Aside from the dynamics, prices and outputs behave as if the system is "competitive" in the sense of the competitive model. The markets appear to be capable of solving not only the problem as posed by competitive theory but also even harder problems. These markets converged to near the equilibrium within an hour after instructions were read to the participants. In essence, the mathematical problem was solved quickly and without all the relevant information existing in a single place. The participants knew only their own parameters and none of the theory. Some sort of parallel processing appears to be taking place but its form remains a mystery.

\section{References}

1. Forsythe, Robert, Thomas R. Palfrey, and Charles R. Plott, "Asset Valuation in an Experimental Market." Econometrica, May 1982, 537-67.

2. _— "Futures Markets and Information Efficiency: A Laboratory Examination." Journal of Finance, September $1984,955-81$.

3. Hoffman, Elizabeth and Charles R. Plott, "The Effect of Intertemporal Speculation on the Outcomes in Seller Posted Offer Auction Markets." Quarterly Journal of Economics, May 1981, 223-41.

4. Johnson, Alonzo, Hsing-Yang Lee, and Charles R. Plott. "Multiple Unit Double Auction User's Manual.” Social Science Working Paper No. 676. Pasadena: California Institute of Technology, June 1988.

5. Lynch, Michael, Ross M. Miller, Charles R. Plott, and Russell Porter. "Product Quality, Informational Efficiency, and Regulations in Experimental Markets." Social Science Working Paper No. 518. Pasadena: California Institute of Technology, January 1984.

6. Miller, Ross M., Charles R. Plott, and Vernon L. Smith, "Intertemporal Competitive Equilibrium: An Empirical Study of Speculation." Quarterly Journal of Economics, November 1977, 599-624.

7. Plott, Charles R., "Externalities and Corrective Policies in Experimental Markets." Economic Journal, March 1983, 106-27.

8. - and Jonathan T. Uhl, "Competitive Equilibrium with Middlemen: An Empirical Study." Southern Economic Journal, April 1981, 1063-71.

9. Williams, Arlington W. and Vernon L. Smith, "Cyclical Double-Auction Markets with and without Speculators." Journal of Business, January 1984, 1-33. 